\title{
An Examination Of The Factor Structure Of The Computer Anxiety Rating Scale
}

Douglas Havelka (E-mail: havelkdj@muohio.edu), Miami University

Fred Beasley (E-mail: beasley@exchange.nku.edu), Northern Kentucky University

\begin{abstract}
This study updates prior research [4] and examines the stability of the factors underlying computer anxiety across time and with a different population of subjects. A factor analysis revealed four distinct factors in the computer anxiety construct: general anxiety toward computer usage, confidence in learning ability, motivation to learn, and power or control of usage. These results validate prior research that found computer anxiety to be a multi-dimensional construct.
\end{abstract}

\section{Introduction}

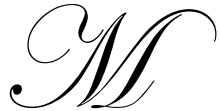

uch attention has been given to the psychological construct computer anxiety as a predictor of successful or effective computer use by individuals [16]. Prior researchers define computer anxiety as a "fear of computers when using the computer or when considering the possibility of computer usage" [5]. Other researchers have variously described computer anxiety as confidence in learning to use computers, anticipation toward computer use, and lack of understanding computers [2]. Research has shown that computer anxiety is significantly related to other psychological constructs such as attitudes towards computers [11], intentions to use computers [6], and to specific behaviors including actual use of computers [18], an individuals' ability to learn new applications [15], and their performance when using a computer [1]. In addition, prior research has found that sweaty palms, dizziness, and an inability to take action are some of the physical symptoms that have been linked to computer anxiety $[2,10,20]$.

Prior research has argued that the detrimental effects of computer anxiety can be mitigated or treated and changed [4]. While some evidence exists that computer anxiety depends on individual characteristics or an individual's prior experience [8], some have suggested that the lack of significant results in these studies is based on the instruments used to measure computer anxiety. Namely, that the instruments used measure a number of different, yet related, constructs and that computer anxiety as a construct is multi-dimensional.

A number of studies have sought to better measure and understand the computer anxiety construct. This study extends that area of research. Specifically, a sample of undergraduate business students was used to conduct a factor analysis of the CARS scale in an effort to increase our understanding of the computer anxiety construct. This study updates the research of Chu and Spires [4] and examines the stability of the factors underlying computer anxiety across time and different subjects. The study explores differences in overall scores and on the underlying dimensions of the CARS scale based on the gender, academic major, computer experience, and age of a sample of undergraduate business students.

\section{Prior Research On Computer Anxiety Scales}

A characteristic of the computer anxiety literature is that a common definition of computer anxiety has not developed. It has been noted that only five measures of computer anxiety have been employed in more than one study [17]. Other studies have simply developed their own unique operational definition of the construct. The most popular scales used to measure computer anxiety have been the 10-item Computer Anxiety Subscale of the Computer Attitude Scale [12], the 20-item Computer Anxiety Scale (CAS) developed by Marcoulides [13], and the 19-item Computer Anxiety Rating Scale (CARS) developed by Heinssen et al. [9]. Chua et al. in their meta-analysis 
of the computer anxiety literature, state that the scales that have measured computer anxiety are "generally reliable, but not compatible" [5]. For example, the CARS scale and CAS scale are quite different instruments supposedly measuring the same construct.

A number of studies have examined the factor structure of these scales. For example, Marcoulides found a two-factor structure in his CAS scale [14]. He labeled these factors "general computer anxiety" and "equipment anxiety" factor. Rosen and Weil performed a factor analysis of a 20-item revised CARS scale and found a threefactor model of computer anxiety [17]. The three factors were labeled "interactive computer learning anxiety", "consumer technology anxiety", and "observational computer learning anxiety." The "interactive computer learning anxiety" factor was said to largely overlap the "general computer anxiety" factor found by Marcoulides. Using an 18-item computer anxiety scale, Todman and Monaghan found two factors - "relaxed" and "in control/competent" [19]. Beckers and Schmidt constructed an instrument that generated a six-factor model of computer anxiety [2]. The dimensions were computer literacy, self-efficacy, physical arousal caused by computers, affective feelings about computers, beliefs about the beneficial aspects of computers, and beliefs about the dehumanizing influences of computers.

Rosen and Weil also found different factor structures when using responses from university students in other countries [17]. This finding not only suggests that cultural differences might impact computer anxiety but also that levels of computer anxiety in a society's population might change as technologies are absorbed into a culture. To summarize these results, computer anxiety has been found to be a multidimensional construct [5]. Beckers and Schmidt in a summary of research that has used factor analysis to study computer anxiety, found the various components of computer anxiety to include fear of computers or anxiety related to using computers, lack of confidence in learning to use computers, lack of understanding of computers, anxiety related to anticipating using a computer, anxiety related to watching others use computers, negative affect toward computers, and concern about the influence of computers in society [2].

\section{Research Method \& Results}

The survey instrument that was used to collect the data on computer anxiety was a modified version of the Computer Anxiety Rating Scale (CARS) [9]. The modified CARS instrument (20-item, five-point scale) and some questions providing demographic information were administered to students enrolled in an introductory MIS course at a large mid-western university. The course is required course of all business majors. A total of 331 surveys (179 men and 152 women) were obtained from three sections of the course. An initial analysis of this data focused on identifying predictors of computer anxiety is presented in Havelka et al. [8].

The scores of the students on the CARS instrument ranged from a low of 20 to a high of 96 (20 and 100 were the absolute possible low and high scores). The mean score was 42.1 (see Table 1). More than 90 percent of the students had a score below the neutral point of 60 , suggesting that the level of computer anxiety in this sample of students is rather low. The items that presented the highest levels of anxiety for the respondents were the "fear of hitting the wrong key and destroying a large amount of information", and "the difficulty of understanding how a computer works."

A study of MBA students using nearly the same modified CARS instrument found that computer anxiety was rather low [4]. The mean total CARS score of 35.82 in that study is actually significantly lower than the mean total CARS score of 42.1 found among the undergraduate students in this study $(\mathrm{z}=6.88, \mathrm{p}<.01)$. Similarly, a study using a sample of students in an introductory psychology class obtained a mean total CARS score of 43.58 [9]. Thus, it appears that computer anxiety among undergraduate college students is low and has been rather stable over time.

A factor analysis (principal components analysis approach with varimax rotation) of the CARS instrument revealed four distinct factors. Only factors with eigenvalues greater than one were retained in the model. Items with factor loadings greater than .5 are found in Table 2. Three items (CA2, CA15 and CA19) were omitted because they had factor loadings less than .5. The first factor seems to reflect a general anxiety toward using computers as well as 
anxiety about gaining new computer-related knowledge. The remaining factors appear to be less directly related to anxiety and fear, but rather seem to describe confidence in a respondent's ability to learn about computers (factor 2), motivation to learn about computers and the importance of computers (factor 3), and perceptions about the power and control of computers (factor 4).

Table 1: The Modified CARS Instrument

\begin{tabular}{|c|c|c|c|}
\hline \multicolumn{2}{|r|}{ Item } & \multirow{2}{*}{$\begin{array}{c}\text { Mean } \\
2.40\end{array}$} & \multirow{2}{*}{\begin{tabular}{c|c} 
SD \\
1.12
\end{tabular}} \\
\hline$\overline{\mathrm{CA} 1-}$ & I feel insecure about my ability to interpret and use new computer applications & & \\
\hline CA2 - & I look forward to using a computer on my job & 2.18 & 0.94 \\
\hline CA3 - & I do not think I would be able to learn a new computer language & 1.98 & 0.87 \\
\hline CA4 - & I am confident I can learn computer skills & 1.76 & 0.82 \\
\hline CA5 - & Anyone can learn to use a computer if they are patient and motivated & 1.98 & 0.85 \\
\hline CA6 - & $\begin{array}{l}\text { Learning to operate a computer is like learning any new skill - the more you practice } \\
\text { the better you become }\end{array}$ & 1.68 & 0.77 \\
\hline CA7 - & $\begin{array}{l}\text { I am afraid that if I begin to use computers I will become dependent on them and lose } \\
\text { some of my reasoning skills }\end{array}$ & 2.10 & 0.91 \\
\hline CA8 - & $\begin{array}{l}\text { I am sure that with time and practice I will be as comfortable working with computers } \\
\text { as I am working with basic word processing software }\end{array}$ & 1.94 & 0.78 \\
\hline CA9 - & I feel that I will be able to keep up with the advances happening in the computer field & 2.26 & 0.86 \\
\hline CA10 - & I dislike working with machines that are smarter than I am & 2.14 & 0.89 \\
\hline CA11- & I feel apprehensive about using computers & 2.25 & 1.02 \\
\hline CA12- & I have difficulty in understanding how a computer works & 2.50 & 1.03 \\
\hline CA13- & $\begin{array}{l}\text { It scares me to think that I could cause the computer to destroy a large amount of } \\
\text { information by hitting the wrong key }\end{array}$ & 2.86 & 1.13 \\
\hline CA14- & I hesitate to use a computer for fear of making mistakes that I cannot correct & 2.08 & 0.92 \\
\hline CA15 - & $\begin{array}{l}\text { You have to be a genius to understand all the special commands contained in most } \\
\text { computer software }\end{array}$ & 2.21 & 0.96 \\
\hline CA16- & If given the opportunity I would like to learn about and use computers & 1.89 & 0.80 \\
\hline CA17 - & $\begin{array}{l}\text { I have avoided computers because they are unfamiliar and somewhat intimidating to } \\
\text { me }\end{array}$ & 1.99 & 0.94 \\
\hline CA18- & I feel computers are necessary tools in both educational and work settings & 1.72 & 0.78 \\
\hline CA19- & The challenge of learning computers is exciting & 2.38 & 0.91 \\
\hline CA20- & I feel that understanding computers will make me a more productive individual & 1.81 & 0.77 \\
\hline TOTAL & & 42.09 & 10.84 \\
\hline
\end{tabular}

The factors found in this study have also been found and discussed in previous studies of computer anxiety $[2,7]$. The four factors found are similar to those found 12 years ago by Chu and Spires [4]. Factor 1 (general anxiety toward computers) is similar to Chu and Spires' Factor A - technical capability", factor 2 (confidence in ability to learn about computers) is similar to Factor D - "learning computer skills", factor 3 (motivation to learn about computers) is similar to Factor B - "appeal of learning about and using computers", and factor 4 (power and control of computers) is similar to Factor C - "being controlled by computers." The biggest difference between the factor structure found in this study and the results of Chu and Spires is that they found an additional, fifth factor which they labeled "traits to overcome anxiety." However, taking the results of both studies into consideration suggests some consistency in the instrument over time and across different populations.

There were some differences in the mean factor scores of students based on their gender, academic major, years using a computer, and age. Regarding gender, there was not a significant difference in the mean total CARS score of men and women in the study. However, looking at specific factors, there was a significant difference in the mean response on factor $1-$ general anxiety toward computers $(t=3.426, \mathrm{df}=326, \mathrm{p}<.001)$. Compared to men, women were found to: 
1. Be more worried about hitting the wrong key and destroying information,

2. Have more difficulty understanding how a computer works,

3. Be more insecure about their ability to use new computer applications, and

4. Feel more apprehensive about using computers.

Table 2 - Factor Analysis with Varimax Rotation

\begin{tabular}{|c|c|c|c|c|}
\hline & \multicolumn{4}{|c|}{ Factor Loadings } \\
\hline & F1 & F2 & F3 & F4 \\
\hline \multicolumn{5}{|l|}{ General anxiety about ability to use computers } \\
\hline CA1 Ability to use new applications & .773 & .124 & -.076 & -.003 \\
\hline CA3 Able to learn language & \begin{tabular}{|l|l|}
521 \\
\end{tabular} & .310 & .075 & .046 \\
\hline CA9 Able to keep up with advances & .516 & .483 & .281 & -.021 \\
\hline CA11 Apprehensive about using & .704 & .218 & .137 & .230 \\
\hline CA12 Difficulty understanding how works & .718 & .183 & .062 & .104 \\
\hline CA13 Hitting wrong key & .596 & -.012 & -.082 & .292 \\
\hline CA14 Fear of making mistakes & .615 & .035 & .435 & .218 \\
\hline CA17 Somewhat intimidating & .715 & .070 & .423 & .022 \\
\hline \multicolumn{5}{|l|}{ Confidence in ability to learn about computers } \\
\hline CA4 Can learn skills & .404 & .697 & .176 & .094 \\
\hline CA5 Can learn computer skills & .108 & .799 & .070 & .064 \\
\hline CA6 Learning...the more you practice & .091 & .788 & .160 & .194 \\
\hline CA8 With time and practice.... & .271 & .628 & .355 & .031 \\
\hline \multicolumn{5}{|l|}{ Motivation/necessity to learn about computers } \\
\hline CA16 Like to learn about and use & .082 & .023 & .773 & .029 \\
\hline CA18 Necessary tools & .068 & .358 & .687 & .118 \\
\hline CA20 Understanding... more productive & .076 & .376 & .621 & .251 \\
\hline \multicolumn{5}{|l|}{ Power and control of computers } \\
\hline CA7 Will become dependent on them & .106 & .113 & .078 & .858 \\
\hline CA10 Dislike...smarter than I am & .392 & .183 & .242 & .561 \\
\hline Percent of variance explained & $22.4 \%$ & $15.4 \%$ & $12.7 \%$ & $7.0 \%$ \\
\hline
\end{tabular}

There were no significant differences in men and women on items that formed the other three factors. This suggests that women may experience some greater level of general computer anxiety, but they do not feel less capable of learning computer skills or are they less motivated to learn about computers. Interestingly, Chu and Spire [4] also found no significant difference in the mean total CARS score of men and women. However, they did find differences between men and women in their responses to the items that comprised their "controlled by computer" factor. Women had more anxiety than men about being controlled by computers. This finding was not replicated in this study (i.e., there was no difference in the mean scores of men and women on factor 4). This might suggest that either men are now as concerned as women about the control computers might have or that the women are now less concerned.

Compared to other business students, students majoring in information systems had significantly lower scores (i.e., lower levels of anxiety) on all four factors $(t$-tests, $p<.05)$. Apparently, students that choose information systems as their major have low general anxiety about computers, high confidence in their ability to learn about computers, and high motivation to learn about computers. Of course, it may also be the case that majoring in information systems tends to reduce anxiety, increase confidence, and increase motivation. This study did not test the causal direction of any of the relationships investigated. 
Students with more experience using computers (greater than 5 years) had significantly lower scores, compared to those with less than 5 years experience, on factor $1-$ general anxiety about computers $(\mathrm{t}=4.77, \mathrm{df}=$ $326, \mathrm{p}<.000)$, and factor 2 - confidence in ability to learn about computers $(\mathrm{t}=2.48, \mathrm{df}=327, \mathrm{p}<.013)$. Thus, experience with computers may affect some components of computer anxiety but not others. Specifically, gaining experience using a computer might reduce computer learning anxiety but have no effect on a person's concern that computers have a negative impact on society. This result is consistent with the findings of Chu and Spires [4]. In their study, students with more experience using computers had lower scores on their "technical capability" factor, which is similar to factor 1 in this study, and they had lower scores on their "learning computer skills" factor, which corresponds to factor 2 in this study. Finally, using a median split, older students were found to have significantly higher scores than younger students on only factor $4(\mathrm{t}=1.97, \mathrm{df}=316, \mathrm{p}<.049)$. Apparently, older students are more likely than their younger counterparts to feel anxiety regarding the controlling, dependency-generating effects of computers today.

\section{Discussion}

Computer anxiety remains an important issue in universities. The concern is that students with computer anxiety will have poor learning experiences in courses that do use computers. The effective treatment and reduction of computer anxiety is dependent on having a valid operational definition of the construct. A feature of the computer anxiety literature is that a common definition of computer anxiety has not developed. It seems that researchers have proceeded on the assumption that the definition of computer anxiety was clear. Differences in the scales used to measure computer anxiety suggest that the definition of computer anxiety perhaps is not so clear. This study sought to better understand one of these scales.

The results of this study indicate that the CARS instrument reflects a rather broad, multidimensional conceptualization of computer anxiety, including the areas of general anxiety about computers, confidence in ability to learn about computers, motivation to learn about computers, and beliefs regarding the power and control of computers. Individuals may experience one or more components of computer anxiety but not others. The results of this study, when compared to the previous research of Chu and Spires [4], indicate that the CARS instrument shows some stability over time and across different samples.

The results also indicate that different aspects of anxiety are being measured by the CARS instrument, and perhaps some of the items may not measure computer anxiety at all. For example, it could be argued that the items found in factor 4 more accurately reflect a negative attitude or uneasy feeling toward computers than any anxiety about using computers. Chu and Spires [4] have also argued that items that examine the appeal of learning about computers (similar to factor 3 in this study) need not be related to computer anxiety. That is, one can have no interest in learning about computers, yet that person need not have anxiety about using computers.

While the factor structure of the CARS instrument may have changed relatively little over time, the instrument may not encompass all of the types of anxiety and concerns that face computer users today. The way we perceive computers and the tasks we undertake using computers have changed, and the computer anxiety scales developed in the 80 s and 90 s may be asking some questions that are not highly relevant today. For example, the modified CARS instrument [4] has items that explore anxiety related to "interpreting computer printout" and learning a "programming language." The Computer Anxiety Scale (CAS) [13] has items that examine computer anxiety related to the use of a typewriter, looking at a high speed printer, and watching someone at a computer terminal. These may not be the main sources of anxiety for computer users today.

Today, much of the activity using computers involves using the internet. Important sources of anxiety for computer users using the internet might include the security of transactions and consumer privacy. These are not components of the CARS instrument. The CARS instrument has items that reflect anxiety regarding understanding how a computer works and how to program a computer, but today people have more of a need to understand how to use a computer to accomplish specific tasks. While computer anxiety as a construct should be stable over time, the operational implementation and definition of the construct should adapt to reflect the actual situations where the construct would apply. 


\section{References}

1. Anderson, A.A. "Predictors of Computer Anxiety and Performance in Information Systems". Computers in Human Behavior, 12 (1). 61-77.

2. Beckers, J.J. and Schmidt, H.G. "The structure of computer anxiety: a six-factor model". Computers in Human Behavior, 17. 35-49.

3. Bradley, G. and Russell, G. "Computer experience, school support, and computer anxiety". Educational Psychology, 17 (3). 25-28.

4. Chu, P.C. and Spires, E.E. "Validating the computer anxiety rating scale: Effects of cognitive style and computer courses on computer anxiety". Computers in Human Behavior, 7 (1/2). 7-21.

5. Chua, S.L., Chen, D.-T. and Wong, A.F.L. "Computer Anxiety and its Correlates: a Meta-Analysis". Computers in Human Behavior, 15 (1). 609-623.

6. Elasmar, M.G. and Carter, M.E. "Use of e-mail by college students and implications for curriculum". Journal of Mass Communication Education, 51 (2). 46-54.

7. Farina, F., Arce, J.S. and Carames, R. "Predictors of anxiety toward computers". Computers in Human Behavior, 7. 263-267.

8. Havelka, D., Beasley, F. and Broome, T. "A study of computer anxiety among business students”. MidAmerican Journal of Business.

9. Heinssen, R.K.J., Glass, C.R. and Knight, L.A. "Assessing computer anxiety: Development and validation of the computer anxiety rating scale". Computers in Human Behavior, 3 (1). $49-59$.

10. Hemby, K.V. "Self-Directedness in Nontraditional College Students: A Behavioral Factor in Computer Anxiety?" Computers in Human Behavior, 14 (2). 303-319.

11. Igbaria, M. and Parasuraman, S. "A path analytic study of individual characteristics, computer anxiety and attitudes toward microcomputers". Journal of Management, 15 (3). 373-388.

12. Loyd, B.H. and Gressard, C. "Reliablity and factorial validity of computer attitude scales". Educational and Psychological Measurement, 44. 501-505.

13. Marcoulides, J.J. "Measuring computer anxiety: The computer anxiety scale". Educational and Psychological Measurement, 49.733-739.

14. Marcoulides, J.J., Mayes, B.T. and Wiseman, R.L. "Measuring computer anxiety in the work environment". Educational Psychology Measurement, 55 (5). 804-810.

15. Martocchio, J.J. "Effects of conceptions of ability on anxiety, self-efficacy, and learning in training". Journal of Applied Psychology, 79 (6). 819-825.

16. Maurer, M.M. "Computer anxiety correlates and what they tell us: A literature review". Computers in Human Behavior, 10 (3). 369-376.

17. Rosen, L.D. and Weil, M.M. "Computer Anxiety: A Cross-Cultural Comparison of University Students in Ten Countries". Computers in Human Behavior, 11 (1). 45-64.

18. Scott, C.R. and Rockwell, S.C. "The effect of communication, writing, and technology apprehension on likelihood to use new communication technologies". Communication Education, 46 (1). 44-62.

19. Todman, J. and Monaghan, E. "Qualitative differences in computer experience, computer anxiety, and students' use of computers: A path model". Computers in Human Behavior, 10 (4). 529-539.

20. Weil, M.M. and Rosen, L.D. "The Psychological Impact of Technology From a Global Perspective: A Study of Technological Sophistication and Technophobia in University Students From Twenty-Three Countries". Computers in Human Behavior, 11 (1). 95-133. 